\title{
Eagle's syndrome: a pain in the neck
}

\section{Síndrome de Eagle: um diagnóstico difícil}

Leonardo Cordenonzi Pedroso de Albuquerque1, Juliana Ávila Duarte², Amalia Izaura Nair Medeiros Klaes², Suelen Mandelli Motaํ', Bárbara Reis Krammer', Larissa Bianchini , Marino Muxfeldt Bianchin ${ }^{1}$

A 60-year-old male patient was evaluated for cervical pain, hiccups, dysphonia and dysphagia for five months. Physical examination showed left IX and X cranial nerve palsy. Brain MRI was normal. A cervical CT scan showed an elongated styloid process and stylohyoid ligament pseudoarthrosis (Figure). Eagle's syndrome is a rare entity caused by abnormal enlargement and ossification of the styloid process, the attached stylohyoid ligament and the lesser cornu of the hyoid bone $\mathrm{e}^{1,2,3,4}$. The condition causes variable degrees of compression of V, VII, IX, X and XII cranial nerves, and the jugular or carotid, leading to diverse symptoms ${ }^{1,2,3,4}$. Eagle's syndrome pathogenesis remains unclear ${ }^{1,2,3,4}$.
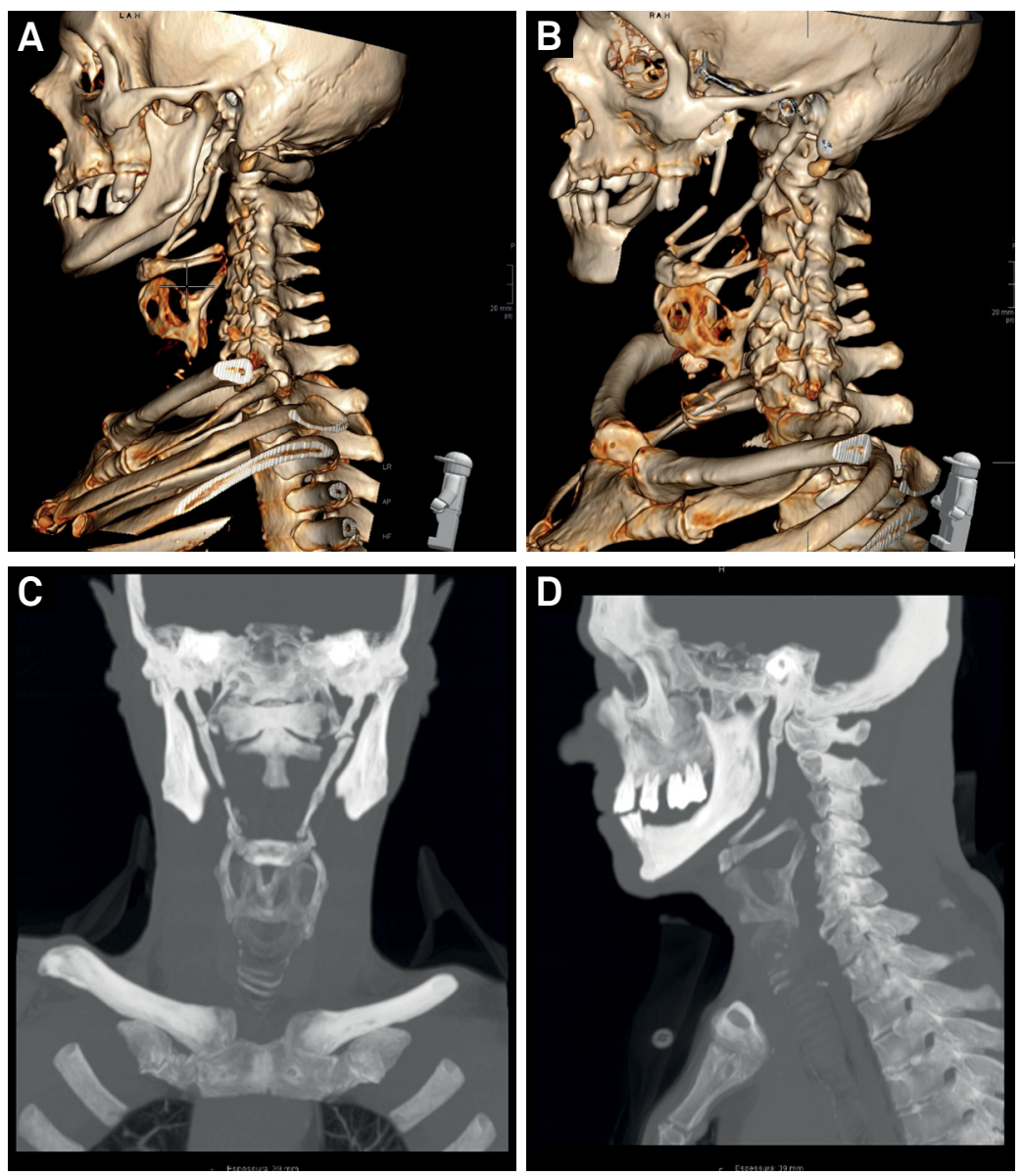

Figure. Maximum intensity projection and 3D CT-scan volume rendering of the patient's cervical region. Note bilateral calcification of the stylohyoid ligament.

\footnotetext{
¿Universidade Federal do Rio Grande do Sul, Hospital de Clínicas de Porto Alegre, Divisão de Neurologia, B.R.A.I.N. (Basic Research and Advanced Investigations in Neurology), Porto Alegre RS, Brasil;

${ }^{2}$ Hospital de Clínicas de Porto Alegre, Serviço de Radiologia e Diagnóstico por Imagem, Porto Alegre RS, Brasil.

Support: Brazilian Government research grant agencies CNPq, FAPERGS and FIPE/HCPA. Bianchin MM is further supported by CNPq (\#307084/2014-0). Correspondence: Marino M. Bianchin; B.R.A.I.N. Experimental Research Centre, Hospital de Clínicas de Porto Alegre; Rua Ramiro Barcelos, 2350; 90035-903 Porto Alegre RS, Brasil; E-mail: mbianchin@hcpa.edu.br

Conflict of interest: There is no conflict of interest to declare.

Received 17 August 2016; Accepted 10 October 2016.
} 


\section{References}

1. Bahgat M, Bahgat Y, Bahgat A. Eagle's syndrome, a rare cause of neck pain. BMJ Case Rep. 2012; pii: bcr2012006278. http://doi.org/10.1136/bcr-2012-006278

2. Costantinides F, Vidoni G, Bodin C, Di Lenarda R. Eagle's syndrome: signs and symptoms. Cranio.. 2013;31(1):56-60. http://doi.org/10.1179/crn.2013.008
3. Fusco DJ, Asteraki S, Spetzler RF. Eagle's syndrome: embryology, anatomy, and clinical management. Acta Neurochir (Wien). 2012;154(7):1119-26. http://doi.org/10.1007/s00701-012-1385-2

4. Piagkou M, Anagnostopoulou S, Kouladouros K, Piagkos G. Eagle's syndrome: a review of the literature. Clin Anat. 2009;22(5):545-58. http://doi.org/10.1002/ca.20804 